\title{
RESILÊNCIA: UM ESTUDO COM BRASILEIROS INSTITUCIONALIZADOS
}

\author{
RESILIENCE: A STUDY VVITH BRAZILIANS FROM \\ INSTITUTIONS
}

\author{
Aparecida Magali de Souza Alvarez ${ }^{1}$ \\ Maria Cecília Leite de Moraes ${ }^{2}$ \\ Elaine Pedreira Rabinovich ${ }^{3}$
}

ALVAREZ, A. M. S.; LEITE DE MORAES, M. C.; RABINOVICH; E. P. Resiliência: Um Estudo com Brasileiros Institucionalizados. Rev Bras. Cresc. Desenv. Hum., São Paulo, 8 (1/2), 1998.

Resumo: A resiliência pode ser definida como a capacidade de um desenvolvimento normal sob condições difíceis ou adversas. Partindo-se desta definição, foi realizado um estudo exploratório objetivando elaborar hipóteses heurísticas para dar conta deste tema a partir do relato livre autobiográfico de sete pessoas que passaram anos de sua infância institucionalizados. Foram consideradas resilientes por manterem vinculações afetivas importantes, por trabalhar, estudar e não ter atividades delinqüenciais. A análise do discurso evidenciou a importancia de aspectos ligados à maternagem através de pontos fixos de valência positiva, que possibilitaram aos sujeitos alguma forma de apego seguro: irmãos; namoradas; parentes; outras pessoas; instituição. Através destes pontos, os sujeitos puderam constituir-se como identidades e individualidades. O estudo apontou também para a paternagem como um fator educativo de "mostrar o caminho", exercida pela instituição através da responsabilizaçao da criança em atividades. Esta paternagem seria a responsável pelo sentimento de potência que pareceu caracterizar os sujeitos. Finalmente, os sujeitos expressaram um desejo de normalização de suas vidas que pode ser interpretado como o direito à equidade, de não exclusão, ou seja, de acesso ao repertório de experiências da sociedade. Estes três aspectos estariam na base da capacidade de criação de sentido da própria vida através de um rumo que norteia projetos unindo o presente ao passado e ao futuro.

Palavras-chave: resiliência; resilientes; maternagem; paternagem; direito à equidade.

\section{INTRODUÇÃO}

A resiliência é um conceito que, em geral, indica um enfrentamento positivo ante a adversidade. Este conceito veio emprestado da fIsica, onde é definido como 'propriedade pela qual a energia armazenada em um corpo deformado é devolvida quando cessa a tensão causadora duma deformação elástica” (Novo Dicionário Aurélio). Seriaum sinonimo de elasticidade, dado o corpo retornar à sua forma original após ter sido torcido, amassado, puxado ou empurrado.

1 Psicóloga, Mestre em Saúde Pública pela Paculdade de Saúde Pública/USP, doutoranda pela FSP/USP pesquisadora do centro de Estudos do crescimento e Desenvolvimento Humano.

2 Terapeuta Ocupacional, Mestre em Saúde Pública pela Faculdade de Saúde Pública/USP, doutoranda pela FSP/USP, pesquisadora do centro de Estudos do crescimento e Desenvolvimento Humano.

3 Psicóloga Clinica, Mestre em Psicologia Experimental, Doutora em Psicologia Social pelo instituto de Psicologia da USP, pesquisadora do centro de Estudos do crescimento e Desenvolvimento Humano.

End. Av. Dr. Arnaldo, 715, subsolo, sala 21, são Paulo - SP - CEP 01246-904 - Telefax: (011) 3061-3572. 
Na literatura psicológica, ele surgiu associado a pessoas que tendo passado por experiências como as dos campos de concentração na II Guerra Mundial, puderam não apenas sobreviver como também atingir uma qualidade de vida satisfatória, após este período. Victor FRANKL, recém falecido, teria sido um dos divulgadores desta idéia, ao relatar em seus livros como enfrentou os anos passados nestes campos e como, a partir desta experiência, delineou uma praxis existencial e psicoterapêutica centrada no sentido da vida.

Conforme relatado anteriormente (MORAES \& RABINOVICH, 1996), o Centro de Estudos do Crescimento e do Desenvolvimento Humano tomou ciência desta área de estudos através de uma pesquisa multicêntrica, coordenada por Edith GROTBERG $(1993,1995)$, objetivando analisar e propor modos de promover a resiliência junto a crianças em diferentes culturas. Neste trabalho, o Brasil foi representado pela pesquisa realizada pelo $\mathrm{CDH}$.

Esta participação despertou o interesse pela temática, resultando no artigo supra citado e em um trabalho de campo, objeto do presente artigo.

No artigo anterior, expusemos os vários usos do termo resiliência conforme a literatura, apontando a falta de clareza conceitual e suas possíveis implicações. Dentre elas, a mais importante referir-se-ia ao conceito ser utilizado como explicação ou como descrição.

O conceito de resiliência utilizado descritivamente opunha-se ao de vulnerabilidade, sendo pares antitéticos que não geravam um conceito heurístico.

No conceito de resiliência utilizado como explicação, não ficava estabelecido tratar-se de uma característica do ambiente, do sujeito ou de ambos, podendo implicar tanto em fatores quanto em processos. Ao utilizar fatores, estes tanto poderiam ser discretos, isolados quanto resultarem de uma interação entre eles.

Além desta falta de clareza conceitual, o método preferencial utilizado nas pesquisas era o questionário, onde o delineamento do objeto de estudo era feito baseado nos estudos anteriores, visando confirmar ou negar hipóteses.

O conceito de resiliência, conforme elaborado pelo $\mathrm{CDH}$, indicou-a como uma saída não depressiva que capacitaria a pessoa a traçar sua própria trajetória (LEFÈVRE, 1995), que pode ser considerada como o desenvolvimento normal sob condições difíceis (RUTTER, 1990).

Tal conceito impôs-se como objeto de estudo ante o quadro social brasileiro, onde $11 \mathrm{mi}$ lhões de pessoas (Ipea, 1996) vivem em estado de pobreza (renda mensal inferior a 1 s.m.). A condição de resiliência perpassaria grande parte da população brasileira, mas estaria mais presente, ou mais vivamente presente, em alguns extratos desta população. Uma das conseqüências de fatores como urbanização crescente, êxodo rural, rupturas de relações familiares e de origem, é o aumento de população desassistida população de rua; população jovem institucionalizada; idosos.

O presente estudo objetivou, de modo exploratório, discutir e analisar o conceito de resiliência. Propusemo-nos investigar um grupo de sujeitos egressos de instituições - internatos, orfanatos - e que poderiam ser considerados resilientes segundo critérios de adequação aos padrões sociais. Partimos, pois, do conceito como um adjetivo, ou seja, como um conceito operacional que nos permitiu delimitar um campo de atuação.

Propusemo-nos, além disto, a examinar o conceito de resiliência de um modo, até então não referido na literatura: através do discurso livre sobre suas vidas. Este método de análise havia sido utilizado em trabalho realizado pelo CDEi com adolescentes e adultos a respeito de um programa de educação sexual em escolas, sendo uma revisão do método desenvolvido por Arakcy Martins RODRIGUES (1994).

Foi nosso objetivo realizar um estudo exploratório para verificar possíveis regularidades existentes nas histórias de vida de pessoas, consideradas resilientes após longa permanência em instituições. O objetivo deste estudo, portanto, foi analisar as condições de vida que teriam possibilitado ajovens que passaram anos de sua infância institucionalizados pudessem ter um desenvolvimento normal. Tomando-se como material de análise o discurso livre sobre suas vidas pretendeu-se fazer emergir as condições facilitadoras ou não, conforme vivenciadas pelos sujeitos. Nesta falta de direcionamento, havia o pressuposto de que estaríamos possibilitando a emergência da resiliência como conceito explicativo e descrevendo o seu processo através dos quais ela se dá.

\section{MÉTODO}

Foram sujeitos do estudo 7 pessoas, 3 do sexo feminino e 4 do sexo masculino, de idades entre 16 e 45 anos, que viveram e/ou vivem em instituicões/orfanatos.

Estes sujeitos foram considerados “resilientes" segundo os seguintes critérios: vinculação afetiva, não delinquência, trabalho regular, sucesso escolar. Portanto, os critérios en- 
volveram o relacionamento positivo dos sujeitos com esferas da vida, pessoal e societária.

Os sujeitos relataram suas histórias de vida em discurso livre (versão adaptada do método desenvolvido por RODRIGUES, 1994), seguido por um questionário aberto sobre dados sóciodemográficos e familiares. As entrevistas foram gravadas em gravadores Panasonic-RQ-L307, após o que foram transcritas literalmente.

Os sujeitos foram contatados por Aparecida Magali de Souza Alvarez, que havia assistido um orfanato onde vários sujeitos estiveram internados, e, também, através de uma Fundação.

As entrevistas foram posteriormente analisadas comparando-se similaridades e diferenças entre os relatos e suas dinâmicas, objetivando-se padrões que se repetiam e/ou se repeliam. Às falas, aplicou-se o método de derivação empírica de categorias de análise, procurando-se elementos de inteligibilidade nos discursos de modo a formar quadros mentais em que certos "padrões" se repetiam ou se repeliam. Estes "padrões" foram, posteriormente, transformados em hipóteses empiricamente derivadas que, retomadas aos discursos, possibilitaram outros padrões e outras hipóteses, em níveis cada vez mais abrangentes.

\section{RESULTADOS E DISCUSSÃO}

O elemento mais genérico desta análise descritiva foi o que denominamos criação de sentido. Através deste sentido, nossos sujeitos expressaram procurar ativamente por algo que lhes daria um rumo.

"estudar sempre... ser alguém na vida, ter profissão... ter uma casa... comprar um carrinho...".

A criação de sentido implicava na própria trajetória da vida, que se construía através de portos, que norteavam as ações. A vida teria seu sentido norteado por um projeto que a impulsionava através de metas que o sujeito, não apenas almejava, como acreditava poder alcançar: portanto, projeto, esperança, potência, poderiam ser consideradas palavras-chave implicadas no que estamos denominando criação de sentido.

"por causa de eu viver em hospitais, eu gostava desta área. Ai eu dizia: quando um dia eu tiver um emprego vai ser na área hospitalar."

Esse elemento descritivo - a criação de sentido - apoiava-se em um fator explicativo: a presença de referências ou pontos fixos.

"Minha vida começou quando eu encontrei meu marido...".

O ponto fixo seria algum marco de referência que permanece, podendo ser uma pessoa, presente ou ausente, real ou fantasiada, uma coisa, um lugar.

"apesar de eu nunca ter morado com minha mãe, eu sentia falta dela.”

Em termos psicológicos, o ponto fixo surge como um aspecto do apego seguro (BOWLBY, 1984), a base de onde a pessoa pode se constituir. “...assim a pessoa diz alguma coisa e eu passo a gostar dela...”

"você tendo namorado não se sente sozinha."

Segundo DAMERGIAN (1988), “o bebê necessita pelo menos um ponto fixo para construir um universo, i.e., seu mundo interno, sua identidade. (...). O ponto fixo é o objeto bom, que deve ser oferecido pelo meio. Sem isto, a personalidade não se desenvolve, a identidade não se constrói. O ponto fixo equivale ao objeto permanente” (p. 291).

"eu tive um apoio, graças a Deus, eu soube aproveitar o apoio que eles me deram."

O ponto fixo, portanto, refere-se a conceitos básicos em psicologia do desenvolvimento, ancorados no pensamento psicanalítico, de um lado, e no pensamento piagetiano, de outro. O que importa ressaltar, no presente momento, é que nossos sujeitos revelaram ter pontos fixos de valência positiva - pontos fixos de ancoragem psíquica com valor de atração - de onde puderam partir e para onde puderam retomar. Como Damergian aponta, trata-se da própria possibilidade de construção da identidade, no sentido de sentimento do eu, que se dá apoiada nestes pontos. Esses pontos possibilitariam uma interlocução eu-mundo, mesmo que fantasiada.

A vinculação afetiva existiria a partir de um(s) ponto(s) fixo(s), assim como o sentimento de pertencimento e a memória que une presente, passado e futuro.

O ponto fixo, conforme estamos utilizando, seria um equivalente à maternagem (WINNICOTT, 1975). Maternagem é o sistema de cuidados que, de uma fusão inicial cuidador-criança, propicia esta mesma separação, instalando a realidade a partir de um campo ilusório compartilhado. Este campo ilusório compartilhado - o espaço potencial - inaugura o possível no lugar do certo, ou seja, a cultura.

O ponto fixo, então, seria equivalente à maternagem, estando relacionado a "lugares" (TUAN, 1983) vistos como centros geradores de valores. Podem ser experiências anteriores boas, que se "ancoram" em outros "portos".

"eu pude agarrar este apoio, tirar o melhor que pude deste apoio.”

Esta hipótese foi trabalhada pela comparação de histórias de vida de irmãos onde o mais 
velho teria fornecido este ponto ao mais novo, sendo também referido reciprocamente.

A maternagem, nestes casos, pareceu residir em uma vivência anterior e interior, reeditada, facilitando futuras "ancoragens".

"tive um amigo muito importante em minha vida, desde que nós tínhamos um ano de idade."

Por outro lado, a imagem de "porto" se completa com a de "barco", ou seja, o que vai, o que parte, o que migra. Observamos que a criação de sentido baseia-se em uma capacidade de ter iniciativa: o poder ir e o ter para onde ir, que seria o "rumo".

Estes atributos seriam o da paternagem como o que "aponta o caminho", o fator educativo. Seria o contexto mais amplo no qual a criança se encontra: a própria instituição em seu funcionamento. A instituição ao permitir à criança vivenciar a tomada de decisões, permite também a responsabilização. Seria o oposto de favorecer uma posição de vitimização: uma posição de dependência passiva, exigente e queixosa. Isto foi possível pela instituição ter permitido a cnança expenenciar o poder, pequeno, que ela tem, dentro da estrutura onde vive.

“foi esse serviço ... saimos um pouco de lá ... conhecemos pessoas diferentes, bem diferentes da gente...”.

Concomitantemente, contudo, levantamos a hipótese de que a vida comunitária pode ocasionar um apego excessivo a um grupo de companheiros, com uma dificuldade de diferenciação deste grupo, com possíveis conseqüências como delinqüência por aderência emocional ao grupo.

"a minha vida e de meus amigos é tudo igual, a mesma coisa, o que um faz o outro faz também".

Portanto, a condição de vida institucionalizada parece carregar consigo um ônus referente à ambivalência entre ser/não ser, em contraposição a uma posição de poder se contrapor ao grupo. Correlatamente, encontramos o silêncio como uma forma de sufocação, em que o que não é dito não pode ser dito por ter sido um silenciamento da própria condição de subjetividade.

Como último aspecto da análise dos discursos, mas não menos importante, está o que denominamos "normalização". Trata-se de um modo de dizer que suas vidas eram tão normais quanto as de outras pessoas.

"minha mae é legal.. é normal”.

"às 5 horas eu fui roubado. Naquele dia eu entendi que eu era uma pessoa normal."

"ela (a mãe) deixou eu e meus irmãos num orfanato. Era como a minha casa."

Esta normalidade é procurada pela experiência no trabalho, no estudo, ao ser roubado ou através das atividades diárias, às quais as pessoas consideradas “normais” têm acesso ou são expostas. Neste sentido, a normalização corresponde ao direito de eqüidade de experiências, independentemente das diferenças interindividuais, respeitada a diversidade.

À luz deste direito, nossos sujeitos expressaram algo importante para todos os grupos sociais de alguma forma excluídos: o direito de poder estar incluídos.

\section{CONCL USÃO}

Este estudo exploratório sobre a resiliência a partir do discurso livre autobiográfico de pessoas que passaram longos períodos de suas vidas em instituições - orfanatos - permitiu aventar a hipótese de que a resiliência seria um resultado entre falares internos e externos cujo produto é a criação de sentido da própria vida através de um rumo que norteia projetos.

Através desta análise, foi visto que as instituições nortearam, modelaram e/ou ajudaram na formação de comportamentos, através do que denominou-se "paternagem”, ou seja, o exercício da função educativa de responsabilizar, dirigir e mostrar o caminho.

Apontou-se também para a "maternagem" através do conceito de ponto fixo de ancoragem positiva. Para os depoentes, existiu/existe uma "mãe idealizada", freqüentemente utilizada para justificar a internação, facilitando a aceitação desta condição. A presença de irmãos implicou em o irmão mais velho assumir o "controle" da família, dentro e fora da instituição. Entre as mulheres, a busca e necessidade de figura masculina pareceu ser uma das forças a dar rumo às suas vidas. Todos citaram vínculo afetivo importante e alguns transferiram este vínculo para o estudo ou trabalho. Destacou-se a importância da família existente ou a ser formada na vida destas pessoas.

Igualmente foi agente facilitador a "negação" de ser/estar institucionalizado, através de uma busca de "normalidade", em que suas vidas foram, para eles, processos de "normalização", significando "ser como todo o mundo", estar dentro dos padrões. A normalização pode ser entendida como o acesso ao repertório de experiências da sociedade, ou seja, o direito à eqüidade.

Este estudo mostrou que o conceito de resiliência merece maior investigação, devendo ser esta ampliada para conter, concomitantemente, observações de campo. Sugere- se a hipótese de "fatores de proteção", de múltipla 
origem, responsáveis pela resiliência, dentre os quais o estudo fez surgir o "ponto fixo” como um conceito heurístico a ser explorado em estudos subseqüentes.

\begin{abstract}
Resilience can be defined as the capacity to have a normal development under difficult or adverse conditions. Based on this definition, a study was carried out aiming to elaborate heuristic hypotheses about this theme from the free autobiographical reports of 7 people who had spent many years of their lives in orphanages. I hey were considered resilients because they had deep affective relationships; they worked, studied and had no delinquent behaviors. The analysis of this material showed the importance of mothering worked out as fixed points of positive valency that enabled some safe attachment: brothers; relatives; friends; institution. Through these points, the subjetcs were able to constitute their identities and individualities. It pointed also to fathering as an educational factor that showed the way, giving the direction. This was accomplished by making the child responsible for some activities in the institution. The $\wedge$ fathering would be responsible for the feeling of potency that seemed to characterize the subjects. Finally the subjects expressed a wish for normalization of their lives that could be interpreted as the right to have equal opportunities. These three aspects would be the basis of their capacity to give sense to their own lives through a direction that guided their projects, linking the present to the past and the future.
\end{abstract}

Key-words: resilience; resilients; mothering; fathering; equal rights.

\section{REFERÊNCIAS BIBLIOGRÁFICAS}

BOWLBY,J.Apego. SãoPaulo, Martins Fontes, 1984.

DAMERGIAN, S. O papel do inconsciente na interação humana - um estudo sobre o objeto em psicologia social. São Paulo,1988. [Tese de Doutorado - Instituto de Psicologia, Universidade de São Paulo].

GROTBERG, E.H. Promoting resilience in children. A new approach. Birmingham, IJniversity of Alabama, 1993.

GROTBERG, E. H. The internationo:l resilience project: promoting resilience in children. OPS/ OMS/Civitan International Research
Center,1995. MORAES, M. C. L. d.; RABINOVICH, E. P. Resiliência: uma discussão introdutória. Rev. Bras. Cresc. Desenv. Hum., 6(1/2): 10-13, 1996.

RODRIGUES, A. M. Instruções para a entrevista. (mimeo, s.d.).

RUTTER, M. Psychosocial resilience and protective mechanisms. In: ROLF, J. et al. (eds.). Risks and protective factors in the development of psychopathology: New York, Cambridge University Press, 1990.

TUAN, L. Y. Espaço e lugar. São Paulo, Difel, 1983.

WINNICOTT, D. W. O brincar e a realidade. Rio de Janeiro, Imago, 1975. 